This document is the accepted manuscript version of the following article: wallis, I., Prommer, H., Berg, M., Siade, A. J., Sun, J., \& Kipfer, R. (2020). The rivergroundwater interface as a hotspot for arsenic release. Nature Geoscience. https://doi .org/10.1038/s41561-020-0557-6

\title{
1 The river-groundwater interface as a hotspot for arsenic release
}

${ }^{* 1}$ College of Science and Engineering, Flinders University, Adelaide, GPO Box 2100, SA 5001, Australia

${ }^{2}$ National Centre for Groundwater Research and Training, Flinders University, Adelaide, GPO Box 2100, SA 5001, Australia

${ }^{3}$ School of Earth Sciences, The University of Western Australia, Crawley 6009, Australia

${ }^{4}$ CSIRO Land and Water, Private Bag No. 5, Wembley WA 6913, Australia

${ }^{5}$ Eawag, Swiss Federal Institute of Aquatic Science and Technology, 8600 Dübendorf, Switzerland

${ }^{6}$ Institute of Biogeochemistry and Pollutant Dynamics, ETH Zurich, 8092 Zurich, Switzerland

${ }^{7}$ Institute of Geochemistry and Petrology, ETH Zurich, 8092 Zurich, Switzerland 
Geogenic groundwater arsenic (As) contamination is pervasive in many aquifers in South and Southeast Asia. It is feared that recent increases in groundwater abstractions could induce the migration of high-As groundwaters into previously As-safe aquifers. Here we study an Ascontaminated aquifer in Van Phuc, Vietnam, located $10 \mathrm{~km}$ SE of Hanoi on the banks of the Red River, which is affected by large-scale groundwater abstraction. We use numerical model simulations to integrate groundwater flow and biogeochemical reaction processes at the aquifer scale, constrained by detailed hydraulic, environmental tracer, hydrochemical and mineralogical data. Our simulations provide a mechanistic reconstruction of the anthropogenically induced spatio-temporal variations in groundwater flow and biogeochemical dynamics and determine the evolution of migration rate and mass balance of As over several decades. We find that the river bed aquifer interface constitutes a biogeochemical reaction hotspot that acts as the main source of elevated As concentrations. We show that sustained As release relies on regular replenishment of river muds rich in labile organic matter and reactive Fe-oxides and that pumping-induced groundwater flow may facilitate As migration over distances of several kilometres into adjacent aquifers.

Geogenic groundwater arsenic (As) contamination is a problem of global significance, with noteworthy occurrences in large parts of the alluvial and deltaic aquifers in South and Southeast $(\mathrm{S} / \mathrm{SE}) \mathrm{Asia}^{1,2}$. Most regional reconnaissance studies show a relation of groundwater As concentrations with depth ${ }^{1}$ and sediment age ${ }^{3}$. Deeper $(>50 \mathrm{~m})$ and therefore commonly 'older' aquifers show significantly lower dissolved As concentrations, while groundwaters in contact with shallower $(<50 \mathrm{~m})$, commonly 'younger' (Holocene) sediments often exceed the World Health Organisation (WHO) guideline value of $10 \mu \mathrm{g} / \mathrm{L}$, sometimes by a factor of 100 . Consequently, targeting low-As aquifers has become the key mitigation strategy for reducing 
human As exposure. However, fears have emerged that As rich groundwater from overlying aquifers could be drawn into currently unaffected aquifers ${ }^{2,4-9}$.

The presence of As in Holocene groundwaters is generally assumed to originate from the recent, As-bearing deposition of sediments that have been transported downstream by rivers draining orogenies such as the Himalayas ${ }^{1,10}$. Microbially-driven reductive dissolution of Fe(III)-oxides by natural organic carbon is assumed to be the primary mechanism for the release of As from these deposited alluvial river flood plain and delta sediments. While there is strong evidence that the relative abundance and reactivity of $\mathrm{Fe}(\mathrm{III})$-oxides and organic carbon plays a key role in controlling As release ${ }^{11}$, the mechanistic understanding of As distribution patterns within the groundwater remains fragmented and poorly constrained ${ }^{1,7}$. This includes uncertainty about the relative importance of different organic matter (OM) sources ${ }^{1}$, such as buried sediment-bound organic matter $(\mathrm{SOM})^{12,13}$, dissolved organic carbon $(\mathrm{DOC})$ inputs to aquifers via wetlands ${ }^{14-16}$, irrigation and its associated recharge of DOC, as well as buried peat layers ${ }^{12,17}$. Furthermore, groundwater As concentrations seldom follow continuous gradients but often show steep variations over small distances with no apparent systematic relationship between solid-phase and dissolved As concentrations ${ }^{4,12,18-20}$. Clearly, As partitioning between the solid and dissolved phases could also be influenced by groundwater flow processes that may impact the evolution of As concentration patterns much stronger than chemical or microbial processes. These and other knowledge gaps hinder the development of a mechanistic understanding of the local-scale controls on As liberation and migration; however, this can potentially be remedied with a holistic exploration of key hydro(bio)geochemical processes through numerical modelling. In this study, we integrate detailed field observations (Tables 2 and 3) from a large number of earlier studies $^{2,4,7,10,21-23}$ to guide the development, and test the plausibility of conceptual and numerical 
models of As mobilisation and transport, which in turn exemplifies the primary controls of As plume formation.

\section{Large-scale groundwater abstraction induces river water intrusion}

For more than 50 years, Hanoi's increasing groundwater demand has fundamentally changed the regional groundwater flow system ${ }^{2,7}$. Under undisturbed conditions, recharge of the Holocene aquifers occurred mainly through the low-permeable clay and silty overburden at relatively low rates $^{14}$, while net annual groundwater flow was directed towards the Red River. However, induced by successively increasing abstraction, hydraulic gradients at the study site have reversed and transformed the Red River locally from a net gaining to a net losing river ${ }^{7}$. Groundwater flow at Van Phuc is now consistently directed in a NW direction towards the cone of depression beneath Hanoi ${ }^{4,7,10}$ (Fig. 1).

Based on the available hydrogeological, hydraulic and ${ }^{3} \mathrm{H} /{ }^{3} \mathrm{He}$ Tri data, we used transient twodimensional numerical simulations of groundwater flow and solute transport to reconstruct the site's groundwater dynamics over a 60-year period. Originating at the river bank and aligned along the main groundwater flow direction, the model successfully mimics the temporally and spatially varying groundwater flow field between the approximate start of the flow reversal (ca. 1950) and today (Fig. 1,2 and 3). The results show that groundwater in the Holocene aquifer is generally of short residence time, ranging from 0 to $\sim 45$ years, except for waters at greater depth (>40m, Fig. 4 and 5). In contrast, the groundwater in the zone occupied by Pleistocene sediments contains neither ${ }^{3} \mathrm{H}$ or ${ }^{3} \mathrm{He}_{\text {Tri, }}$, implying that the water infiltrated before nuclear bomb testing, i.e., $>55$ years ago (Fig. 1 and 3). In agreement with van Geen et al. (2013) ${ }^{7}$ the ${ }^{3} \mathrm{H}-{ }^{3} \mathrm{He}_{\text {Tri-constrained }}$ 
simulations suggest that groundwater flow velocities in the Holocene aquifer increased from $<1 \mathrm{~m} / \mathrm{yr}$ in 1950 to an average of $40 \mathrm{~m} / \mathrm{yr}$ to date.

\section{River mud deposits as biogeochemical reaction hotspot}

Building on the groundwater flow simulations, multiple plausible conceptual and numerical model variants for the site's reactive transport processes were investigated (CM1-CM6, Table 1 and Fig. 2, 4 and 5). Variant $\mathrm{CM} 6$ included the most comprehensive range of biogeochemical reactions and the entire range of potential organic carbon sources within the investigated system. This scenario served as the basis for an inversion process, which included the joint calibration of flow, solute and reactive transport parameters, followed by a linearised uncertainty assessment for all model parameters (see methods, Table SI5 and SI6). This procedure revealed independently which processes contributed most likely to the field-observed flow and geochemical patterns and isolated the most plausible conceptual model. This verifiable procedure resulted in a firm mechanistic understanding of today's observed groundwater As distribution pattern within the Holocene aquifer and its evolution over the past 60 years (Fig. 3 to 5).

The core of the biogeochemical reaction network that was found to best describe the observations encompasses (i) OM mineralisation under aerobic, denitrifying, sulphate-reducing and Fe-reducing conditions, (ii) precipitation as well as reductive dissolution of Fe(III)-oxides, (iii) calcite dissolution and precipitation and (iv) surface complexation reactions of As with Fe(III)oxides. The last process is not only important to explain As release and immobilisation, but also the time-varying spatial distribution of sorbed and dissolved As mass within the aquifer. The 
inversion process revealed further that organic carbon sources had a clearly different reactivity depending on their lithological association. SOM reactivity in the Holocene sands was revealed to be negligible, while reactivities were distinctively higher in the clay/silt deposits ( $0.06 \mathrm{mM} \mathrm{C/yr)}$ and higher again by a factor of $\sim 30$ in the river muds.

Plotting the dissolved concentrations of key reactive species as a function of groundwater residence time calculated from ${ }^{3} \mathrm{H}$ and ${ }^{3} \mathrm{He}$ tri concentrations (Fig. 4) and as a function of distance from the river (Fig. SI7), summarises the trends of simulated and observed hydrochemical changes. It is evident that the steepest concentration gradients occur in proximity of the river bank, i.e., within the recently recharged groundwaters. Here, the dissolved oxidants $\mathrm{O}_{2}, \mathrm{NO}_{3}{ }^{-}$and $\mathrm{SO}_{4}{ }^{2-}$ that are contained in the intruding Red River water, together with $\mathrm{Fe}(\mathrm{III})$-oxides, get consumed rapidly alongside significant increases in the concentrations of $\mathrm{Ca}, \mathrm{HCO}_{3}{ }^{-}, \mathrm{As}_{\text {tot }}, \mathrm{Fe}^{2+}$, $\mathrm{NH}_{4}{ }^{+}$and $\mathrm{P}$. Besides the concentration changes that are directly associated with the primary redox reactions, calcite and silica dissolution also proceed such that overall the electrical conductivity (EC) rapidly increases from $300 \mu \mathrm{S} / \mathrm{cm}$ (river) to $>1000 \mu \mathrm{S} / \mathrm{cm}$ in the groundwater. Thereafter, data scatter around the resultant elevated concentrations mark groundwater of longer residence time that infiltrated the Holocene aquifer between 10 and 50 years ago (Fig. 4). Superimposed on this trend are local concentration variations induced by the mineralisation of OM hosted in the silt/clay deposits capping the Holocene sands and the diffusional influx of affected solutes (e.g., $\mathrm{HCO}_{3}{ }^{-}$and $\mathrm{Fe}_{\text {tot }}$, Fig. 4).

The observed and simulated steep concentration gradients in proximity to the river bank strongly suggest that the river mud deposits act as a biogeochemical reaction hotspot in which the regular deposition of not only As-containing Fe(III)-oxides but also of highly reactive organic 
carbon plays a key role. Induced by the rapid OM degradation, reductive dissolution of $\mathrm{Fe}(\mathrm{III})$ oxides leads to a successive loss of sorption sites, which fuels sustained As release at and near the river-groundwater interface to form the As plume that is now observed in the aquifer. In contrast, slow infiltration of organic-rich water through the overlain clay and silt deposits constitutes a relatively minor contribution to As release (Fig.2 and Table SI4). While these clay and silt deposits contain elevated concentrations of OM $\left(0.01-0.82 \mathrm{wt} \%\right.$ at $\left.0-25 \mathrm{mbg}^{23}\right)$ and porewater with elevated concentrations of $\mathrm{As}_{\text {tot }}, \mathrm{Fe}^{2+}, \mathrm{NH}_{4}{ }^{+}, \mathrm{HCO}_{3}{ }^{-}$and $\mathrm{P}$, consistent with those of many As source zones, the water flux from these low-permeable deposits is too low to provide a significant impact on the overall As mass flux in the Holocene aquifer $(<5 \%)$.

Finally, our modelling results suggest that the SOM prevailing in the Holocene aquifer (Table SI4) contributes only minimally to the As mass budget. If an elevated SOM reactivity in the Holocene aquifer was assumed (model variant $\mathrm{CM} 5$ ), the steep concentration gradients near the riveraquifer interface could not be reproduced. Instead, a steady and continuous increase in concentrations occurred along the flow path (Fig. 4e). Therefore, in-situ As release by Fe(III)oxide reduction plays a minor role in the formation of the As plume compared to the contribution from As release at the river-groundwater interface. This finding is consistent with the unvaryingly low SOM concentrations found in the Holocene aquifer (<0.03 wt\%, Fig. SI1).

Identifying the river-groundwater interface as a biogeochemical reaction hotspot is corroborated by earlier observations in the region, including laboratory incubation experiments documenting extensive As release from saturated near-surface sediments of the Mekong Delta but little As release from deeper aquifer sediments ${ }^{16}$. The reactivity of native SOM was found to be 
insufficient to fuel significant reductive dissolution of the native Fe(III)-oxides in the deeper clays and aquifer sands. In-situ As release measurements within river muds along the Red River ${ }^{10}$ and incubation experiments with Red River sediments from other sites $^{24}$ also support our finding.

\section{Arsenic plume dynamics}

Emerging from the As release hotspot at the riverbed, water enriched in As successively displaced the ambient groundwater that prevailed in the fluviatile sediments prior to 1950 . The most plausible conceptual/numerical model (CM6), which produced the closest match to observed concentration patterns (Table SI5), suggests that the currently observed spatial distribution of groundwater As can be linked to the successively increasing rates of river water intrusion. Starting with the intrusion of river water into the Holocene aquifer, dissolved As concentrations at the river-groundwater interface increased to $>500 \mu \mathrm{g} / \mathrm{L}$ (Fig.3-5). The simulations illustrate that the front of the As plume has migrated $>1700$ m over the last 60 years, from the river-groundwater interface to its current position.

The ratio of the rates of river water infiltration and net As release from the hotspot, in combination with the adsorption affinity of the Fe-oxides in the Holocene sands thereby governs the total As plume mass and its front propagation with time. As release rates from the river muds remain below our model-estimated As replenishment rate of $0.003 \mu \mathrm{M}$ As/day until 20 years after commencement of pumping in Hanoi (Fig. SI11). In the subsequent years, however, with advective velocities exceeding $8.8 \mathrm{~m} / \mathrm{yr}$, As release started to surpass As replenishment, subsequently resulting in a slow depletion of the river-mud As pool. At the end of the simulation period, the net As release rate increased to $\sim 0.017 \mu \mathrm{M}$ As/day, with the overall As pool 
diminishing to $\sim 60 \%$ of its initial mass. The decreasing As pool will ultimately lead to an increased dilution of the released As and decreasing dissolved As concentrations within the Holocene aquifer, as observed for a study site in Nam Du, east of $\mathrm{Hanoi}^{25}$. Our modelling results infer that river mud replenishment is required to allow for a sustained As release over the entire simulation period.

In addition to As release from river muds, in-situ release of As also emerged within the Holocene sands as a consequence of river water intrusion. Interestingly, this release, while predominantly linked to the displacement of As from Fe-hosted sorption sites, occurs in the absence of excessive reductive dissolution of Fe-oxides. The differing hydrochemical characteristics of the intruding river water, in particular the elevated phosphate concentrations that originate from OM mineralisation at the groundwater-river interface, reduce the affinity for As sorption. This decreased affinity causes the aqueous As plume mass to increase, and to spread at a faster rate than if reductive dissolution of Fe-oxides would be the sole source of As. Simultaneously, but spatially apart, released As is partially resorbed downgradient of the plume front (Fig. SI8 and SI9). While As in-situ release initially provided a negligible contribution to the overall As plume mass, its overall contribution increased over time to $\sim 35 \%$ (Fig.2, Table SI4) as the infiltrating river water occupied steadily increasing volumes of the Holocene aquifer, with the remainder originating from river muds. The modelling results suggest an average As release of $0.1 \mu \mathrm{M} / \mathrm{yr}$, which compares well with experimentally determined rates of $0.02-0.35 \mu \mathrm{M} / \mathrm{yr}$ for Holocene sediments north of $\mathrm{Hanoi}^{3}$ and $0.18 \mu \mathrm{M} / \mathrm{yr}$ for a site north-west of Hanoi ${ }^{30}$ (Fig. SI12).

\section{Physico-chemical controls of arsenic release rates}


Despite the increase in river water intrusion over the last $~ 60$ years, the $\mathrm{OM}$ degradation rate in the river muds remained approximately constant $(1.9 \mathrm{mM} \mathrm{C} / \mathrm{yr}$, Fig. SI11) due to sustained Fereduction. The simulated average net As release rate within the river muds is in the range of 6 $\mu \mathrm{M} / \mathrm{yr}$. This model-estimated rate is in good agreement with the experimentally determined rate of Stahl et al $(2016)^{10}$, who measured net As release rates at the river-aquifer interface that ranged between $<0.15$ and $55 \mu \mathrm{M} / \mathrm{yr}$, while laboratory incubations demonstrated that As release from river muds at other locations can reach rates of $>500 \mu \mathrm{M} / \mathrm{yr}^{24}$. These model-identified As release rates need to be understood in the context of river geomorphology ${ }^{10}$. The upstream end of our study site, i.e., the location where the river water intrusion occurs, is located within an active depositional environment containing highly reactive OM resulting in a high net As release rate (Fig.2). In contrast, aquifer sections located adjacent to erosional riverine environments were shown to be dominated by older sediments of lower reactivity and net As release ${ }^{10}$.

Biogeochemical hotspots are defined as "areas that show disproportionately high reaction rates relative to the surrounding area" ${ }^{26}$. They emerge (i) where a convergence of flowpaths and mixing of reactants occurs or (ii) at terrestrial-aquatic interfaces where hydrologic flowpaths carry a reactant into an adjacent zone where a (immobile) substrate resides ${ }^{26}$. In our case, the large-scale groundwater abstractions of Hanoi's waterworks have altered hydrologic flowpaths by inducing an advective flux of surface water across the bed of the Red River into the Holocene aquifer, creating a new hotspot for As release. In the context of carbon and nitrogen cycling, river muds have previously been recognised as important biogeochemical reaction hotspots where terrestrial-aquatic interfaces are characterised by high biogeochemical turnover rates ${ }^{26-31}$. 
Our study shows and quantifies, that the formation of As hotspots is facilitated by (i) the continuous co-deposition of labile organic carbon and As-hosting reactive Fe-oxides in depositional zones along the river bank and (ii) an advective flux that draws As-enriched porewater at the river-groundwater interface deeper into the aquifer. Substantial As release, however, only occurs where the flux of soluble electron acceptors supplied by the river water is consumed rapidly enough by the labile OM to allow for the occurrence of Fe-reducing conditions. Similar hotspots are also expected to develop at the interface between aquifers and geomorphic features such as wetlands ${ }^{14,16}$, ponds and irrigation channels ${ }^{15}$, where labile material is replenished, effective hydrological pathways exist, and the time-scales of electron donor and acceptor consumption favour the establishment of Fe-reducing conditions. Otherwise, features such as buried peat layers or organic-rich clays may not act as hotspots if their low hydraulic conductivity prevents the rapid delivery of reactants. In such cases, mass fluxes into and from these features remain low. For the Van Phuc site, this is illustrated by the model-based estimate that the organic-rich clay layer, which overlies the Holocene aquifer, has contributed $<5 \%$ to the overall As plume mass (Fig.2 and Table SI4).

The complex hydrogeochemical interactions that can be addressed by our numerical framework are illustrated in Fig.6. It summarises the prerequisites and the varying influences of these key factors on the emergence of As hotspots as well as the geomorphological controls on their life time. The modelling results show that the sensitivity of As plume formation and the release dynamics of As is a function of four key factors, (i) OM abundance/reactivity (ii) Fe-oxide abundance/reactivity (iii) advective flow rates, and (iv) river mud deposition rate. It is also suggested that in the absence of a sufficiently high river mud replenishment rate only an As "hot 
242 moment $^{26}$ develops with an initial As release peak followed by successively decreasing As 243 concentrations at the river groundwater interface.

245 Overlooking the critical role of flow and solute transport explains why many As affected areas 246 have failed to exhibit a relationship between sediment-bound and dissolved As concentrations.

247 That is why hydraulic, hydrological and biogeochemical processes must be explicitly considered 248 and integrated to explain the variability of As concentrations within and between aquifers. For 249 the investigated site, we have shown how integrated flow and reactive transport modelling has 250 facilitated a more precise, mechanistic understanding of the processes that control the dynamics 251 of As concentration in space and time. Such a mechanistic understanding and its translation into 252 process-based models to frame As migration rates is crucial for the development of safe and 253 sustainable water management strategies. 
2571 Fendorf, S., Michael, H. A. \& van Geen, A. Spatial and temporal variations of groundwater 258 arsenic in South and Southeast Asia. Science 328, 1123-1127 (2010).

2592 Winkel, L. H. et al. Arsenic pollution of groundwater in Vietnam exacerbated by deep 260 aquifer exploitation for more than a century. Proceedings of the National Academy of Sciences 261 108, 1246-1251 (2011.

2623 Postma, D. et al. Groundwater arsenic concentrations in Vietnam controlled by sediment 263 age. Nature geoscience 5, 656-661 (2012).

2644 Berg, M. et al. Hydrological and sedimentary controls leading to arsenic contamination of 265 groundwater in the Hanoi area, Vietnam: the impact of iron-arsenic ratios, peat, river bank 266 deposits, and excessive groundwater abstraction. Chem Geol 249, 91-112 (2008).

2675 Radloff, K. et al. Reversible adsorption andflushing of arsenic in a shallow, 268 Holoceneaquifer of Bangladesh. Applied Geochemistry 77, 142-157 (2017).

2696 Neumann, R. B. et al. Anthropogenic influences on groundwater arsenic concentrations in 270 Bangladesh. Nature Geoscience 3, 46 (2010).

2717 van Geen, A. et al. Retardation of arsenic transport through a Pleistocene aquifer. Nature $272501,204-207(2013)$.

2738 Khan, M. R. et al. Megacity pumping and preferential flow threaten groundwater quality. $274 \quad$ Nature communications 7, 12833 (2016).

2759 Michael, H. A. \& Khan, M. R. Impacts of physical and chemical aquifer heterogeneity on 276 basin-scale solute transport: Vulnerability of deep groundwater to arsenic contamination in 277 Bangladesh. Advances in water resources 98, 147-158 (2016). 
27810 Stahl, M. O. et al. River bank geomorphology controls groundwater arsenic 279 concentrations in aquifers adjacent to the Red River, Hanoi Vietnam. Water Resources Research $280 \quad 52,6321-6334(2016)$.

28111 McArthur, J., Ravenscroft, P., Safiulla, S. \& Thirlwall, M. Arsenic in groundwater: testing 282 pollution mechanisms for sedimentary aquifers in Bangladesh. Water Resources Research 37, $283 \quad 109-117$ (2001).

12 McArthur, J. et al. Natural organic matter in sedimentary basins and its relation to arsenic 285 Geochem 19, 1255-1293 (2004).

13 Meharg, A. A. et al. Codeposition of organic carbon and arsenic in Bengal Delta aquifers. Environ Sci Technol 40, 4928-4935 (2006).

14 Postma, D. et al. Arsenic in groundwater of the Red River floodplain, Vietnam: controlling geochemical processes and reactive transport modeling. Geochim Cosmochim Ac 71, 5054-5071 291 (2007). wetland sediments as a source of arsenic release to ground water in Asia. Nature 454, 505-509 294 (2008). metabolically limited to permanently water-saturated soil in Mekong Delta. Nature Geoscience 9, 29770 (2016). human health threat. Environ Sci Technol 35, 2621-2626 (2001). 
30018 Harvey, C. F. et al. Arsenic mobility and groundwater extraction in Bangladesh. Science

301

302

303

304

305

306

307

308

309

310

311

312

313

314

315

316

317

318

319

320

321

298, 1602-1606 (2002).

19 Horneman, A. et al. Decoupling of As and Fe release to Bangladesh groundwater under reducing conditions. Part 1: Evidence from sediment profiles. Geochim Cosmochim Ac 68, 34593473 (2004).

20 Islam, F. S. et al. Role of metal-reducing bacteria in arsenic release from Bengal delta sediments. Nature 430, 68-71 (2004).

21 Eiche, E. Arsenic Mobilization Processes in the Red River Delta, Vietnam: Towards a Better Understanding of the Patchy Distribution of Dissolved Arsenic in Alluvial Deposits. Karlsruher Mineralogische und Geochemische Hefte, Vol. 37. KIT Scientific Publishing, Karlsruhe, Germany (2009).

22 Frei, F. Groundwater Dynamics and Arsenic Mobilization near Hanoi (Vietnam) Assessed Using Noble Gases and Tritium. ETH Swiss Federal Institute of Technology, Department of Environmental Sciences. Zurich, Switzerland (2007).

23 Eiche, E. et al. Origin and availability of organic matter leading to arsenic mobilisation in aquifers of the Red River Delta, Vietnam. Appl Geochem 77, 184-193 (2017).

24 Postma, D. et al. Mobilization of arsenic and iron from Red River floodplain sediments, Vietnam. Geochim Cosmochim Ac 74, 3367-3381 (2010). doi:DOI 10.1016/j.gca.2010.03.024

25 Postma, D. et al. Fate of Arsenic during Red River Water Infiltration into Aquifers beneath Hanoi, Vietnam. Environ Sci Technol 51, 838-845 (2017).

26 McClain, M. E. et al. Biogeochemical hot spots and hot moments at the interface of terrestrial and aquatic ecosystems. Ecosystems 6, 301-312 (2003). 
323 landscape nutrient processing. Water Resources Research 53, 5038-5056 (2017).

32428 Hedin, L. O. et al. Thermodynamic constraints on nitrogentransformations and other 325 biogeochemicalprocesses at soil-stream interfaces. Ecology 79, 684-703 (1998).

32629 Kocar, B.D. and Fendorf, S. Arsenic Release and Transport in Sediments of the Mekong 327 Delta. In Interdisciplinary Studies on Environmental Chemistry-Environmental Pollution and 328 Ecotoxicology. (2012). Eds. M. Kawaguchi, K. Misaki, H. Sato, T. Yokokawa. T. Itai, M. Nguyen, J. 329 Ono, and S. Tanabe. Pp 117-124.

33030 Larsen, F. et al. Controlling geological and hydrogeological processes in an arsenic 331 contaminated aquifer on the Red River flood plain, Vietnam. Applied Geochemistry 23, 30993323115 (2008). 


\section{Acknowledgements}

This study was supported by the Swiss National Science Foundation (SNSF, grant no. IZKOZ2_ 150435/ IZK0Z2_150435/1; and SNSF, grant no. 167821) and the German Research Foundation (DFG, grant no. 320059499). Mason O. Stahl, Union College, NY; Ben Bostick and Alexander van Geen, Columbia University, US contributed to this work through helpful discussions on previous work at the field site. Pablo Ortega prepared Figure 1.

\section{Author Information}

Corresponding Author: Dr. I Wallis College of Science and Engineering, Flinders University, Adelaide, GPO Box 2100, SA 5001, Australia; email: ilka.wallis@flinders.edu.au

Jing Sun's Present Address: State Key Laboratory of Environmental Geochemistry, Institute of Geochemistry, Chinese Academy of Sciences, Guiyang, 550081, China

\section{Author Contributions}

R.K., M.B., I.W. and H.P conceived the study. M.B and R.K. provided hydrochemical and tracer data and contributed to the groundwater age, hydraulic and hydrogeochemical interpretation. I.W and H.P carried out the flow and reactive transport modelling and J.S., M.B., R.K, I.W and H.P contributed to the development of the geochemical conceptual model underpinning the numerical model. A.S. undertook flow and solute transport model calibration and contributed to model uncertainty analysis. All authors contributed to writing and editing the paper. 


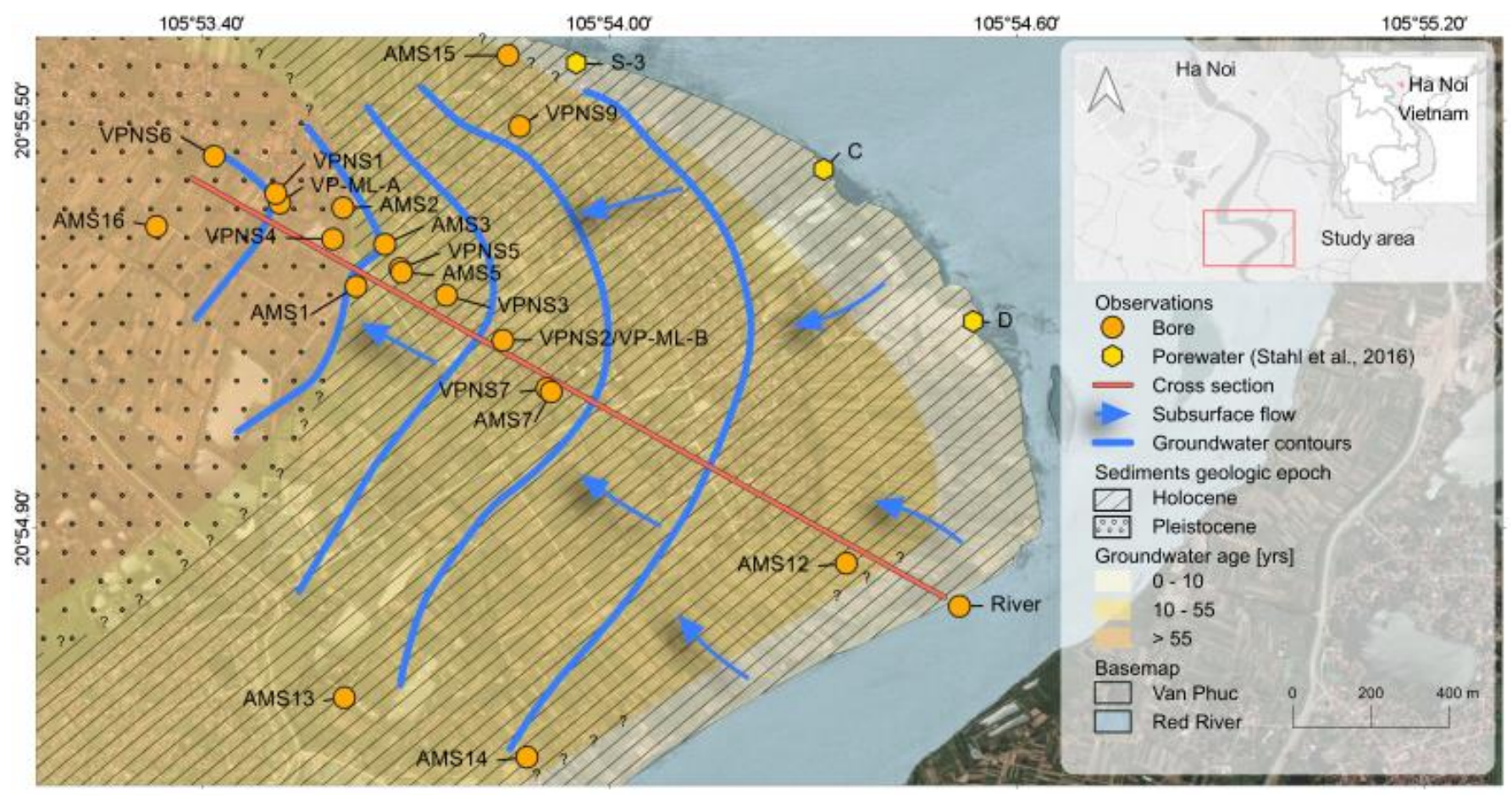

2 Fig. 1: Field site, observation bores and approximate distribution of Holocene and

3 Pleistocene sediments in the study area (reproduced after van Geen et al., 201377).Water

4 level contours assessed on the basis of hydraulic heads (head data from November 2006

5 and June 2010) and main groundwater flow direction; groundwater ages inferred from ${ }^{3} \mathrm{H}-$

$6{ }^{3} \mathrm{He}_{\mathrm{Tri}}$ concentration data. Orange line: Location of modelled cross section. 


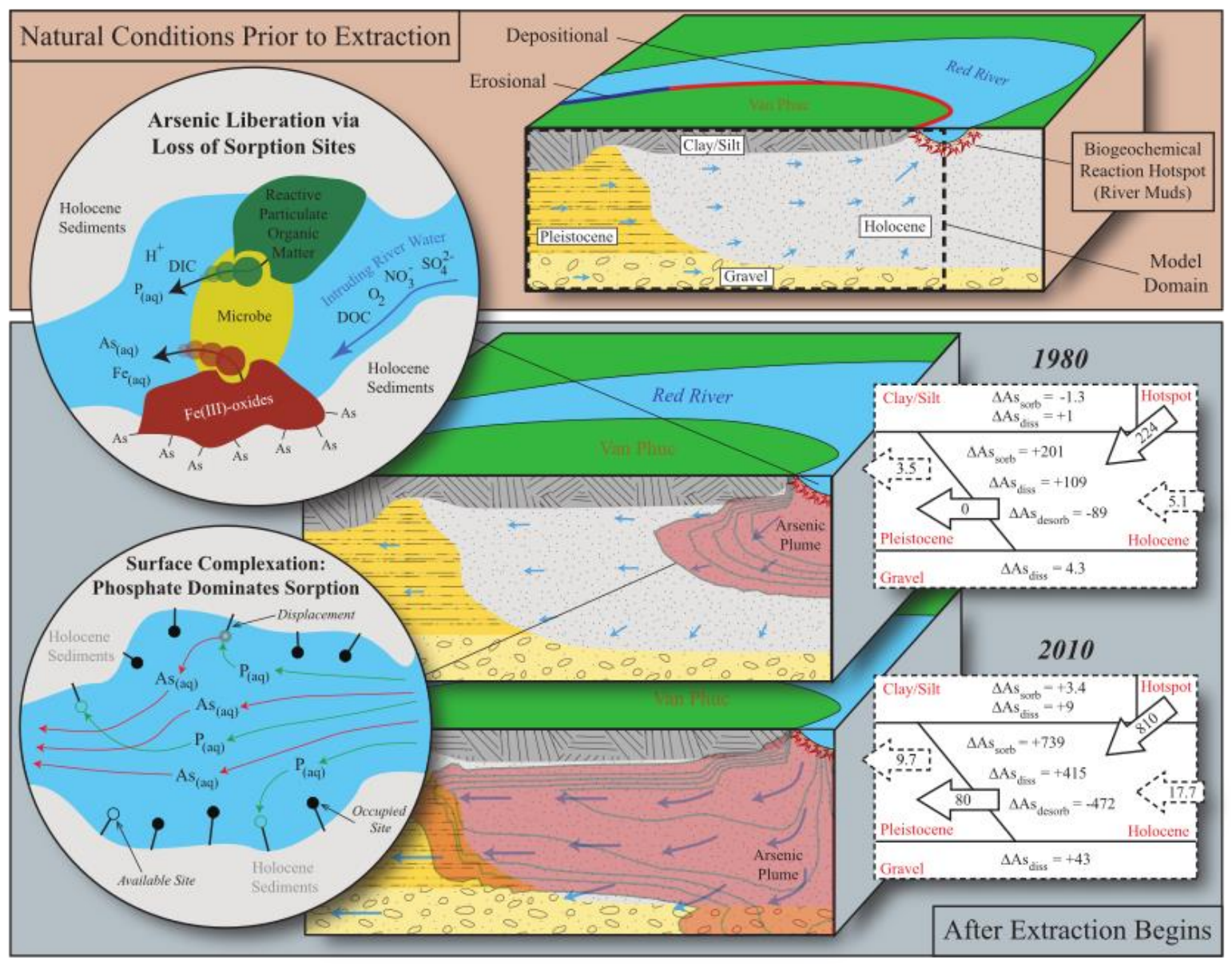

9 Fig. 2: Conceptual model of arsenic plume evolution at Van Phuc. Successive increases in groundwater abstraction since the 1950s have induced a reversal of the natural

11 groundwater flow direction and the influx of riverine water into the Holocene aquifer, giving rise to a hotspot for arsenic release. Sustained As release from the hotspot relies on a continuous co-deposition of labile organic carbon and As-hosting reactive Fe-oxides in depositional zones along the Red River. Advective fluxes draw the As-enriched porewater at the river-groundwater interface into the aquifer where an As plume is formed. The influx/outflux of As from river-muds and over aquifer boundaries are displayed for two time

17 intervals as well as the resulting change in released (A $s_{\text {diss}}$ ), adsorbed (Assorb) and desorbed arsenic mass (Asdesorb) for the Holocene sands; the gravel deposits and the clay/silt overburden. (further details in SI). 

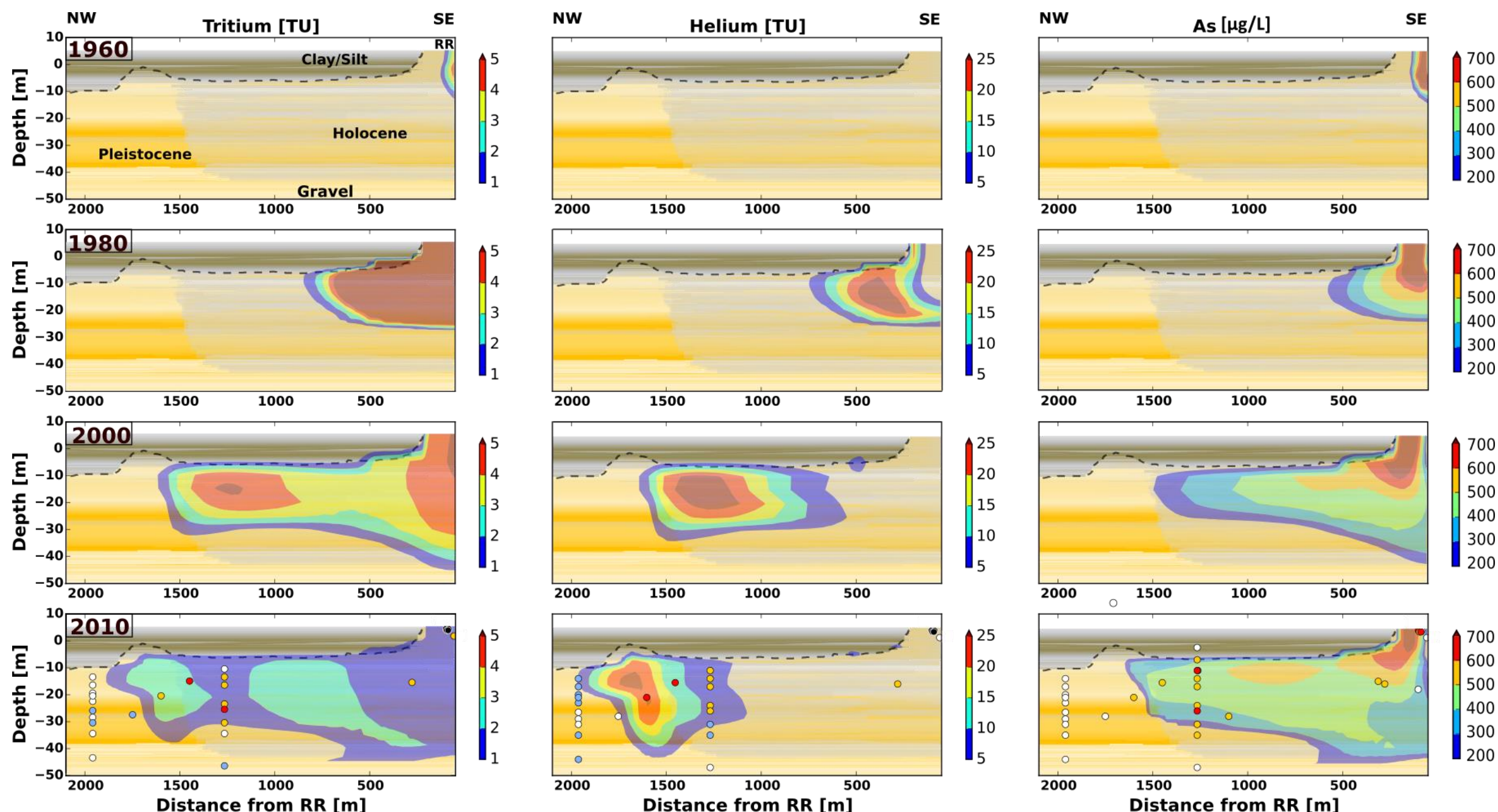

- $>10$ TU

$\circ 1-10 \mathrm{TU}$

- age estimate from Stahl et al (2016)

- $>10$ TU

$\circ-10$ TU
$\circ>0-5$ TU

- age estimate from Stahl et al (2016)
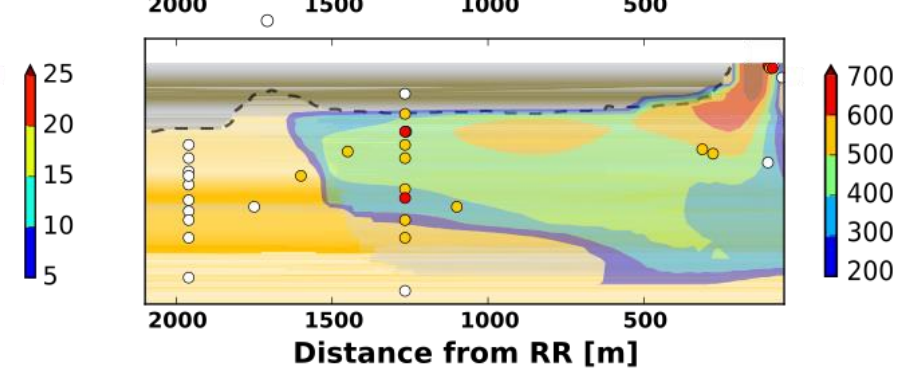

- $500->1000 \mu \mathrm{g} / \mathrm{L}$

$050-500 \mu \mathrm{g} / \mathrm{L}$ 
22 Fig. 3: Concentration of simulated ${ }^{3} \mathrm{H}-{ }^{3} \mathrm{He}$ Tri $[\mathrm{TU}]$ and Astot [ $\left.\mu \mathrm{g} / \mathrm{L}\right]$ [1960 to 2010] along the cross-section from the Red River towards 23 the NW (observations -see Fig. 1 - as coloured dots showing observed concentrations). Simulations of groundwater flow and solute 24 transport, constrained by hydraulic and ${ }^{3} \mathrm{H}-{ }^{3} \mathrm{He}$ Tri measurements, reconstruct the groundwater dynamics over a 60 -year period 25 between the approximate start of pumping-induced flow reversal (ca. 1950) and today. Groundwaters in the Holocene aquifer are 26 generally 'young',( 0 to $\sim 45 \mathrm{yrs}$ ), while groundwaters in Pleistocene sediments contain broadly no ${ }^{3} \mathrm{H} /{ }^{3} \mathrm{He}$ Tri, suggesting water 27 infiltrated before the atmospheric bomb tests (i.e., >55 years). The currently observed pattern of dissolved As can be linked to the 28 successively increasing river water intrusion in response to Hanoi's growing water demand. 

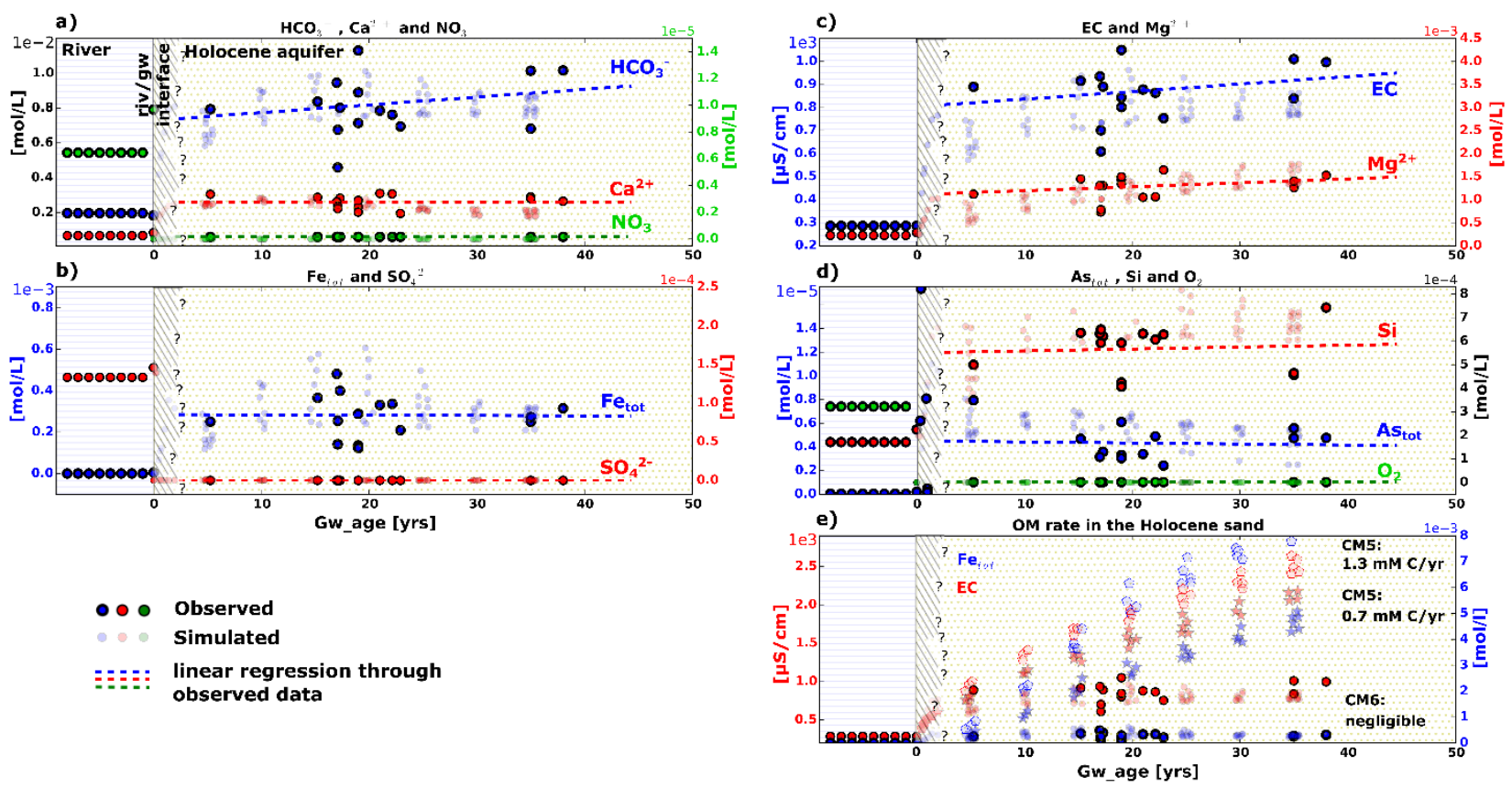

Fig. 4: Observed (see Stahl et al. $2016^{10}$ and Table SI1 andSI2) and simulated (CM6 model variant) concentrations vs apparent ${ }^{3} \mathrm{H}-{ }^{3} \mathrm{He}$ Tri age (panels a-d) from river to Holocene groundwater; e) EC and Fetot under varying organic matter degradation rates within the Holocene sands (CM5 and CM6). Concentrations in [mol/L], EC in $[\mu \mathrm{S} / \mathrm{cm}]$. Simulated concentrations (faint dots) are shown for all model cells with ${ }^{3} \mathrm{H}-$ ${ }^{3} \mathrm{He}_{\text {Tri }}$ ages of $5,10,15,20,25,30$ and 35 years, respectively within the depth range of $17-45 \mathrm{~m}$, consistent with the depth range of observation bores, resulting in a point cloud of simulated concentrations for each groundwater age group. Simulated concentrations in the river muds are based on model cells with ${ }^{3} \mathrm{H}-{ }^{3} \mathrm{He}$ Tri ages $<2 \mathrm{yrs}$. 


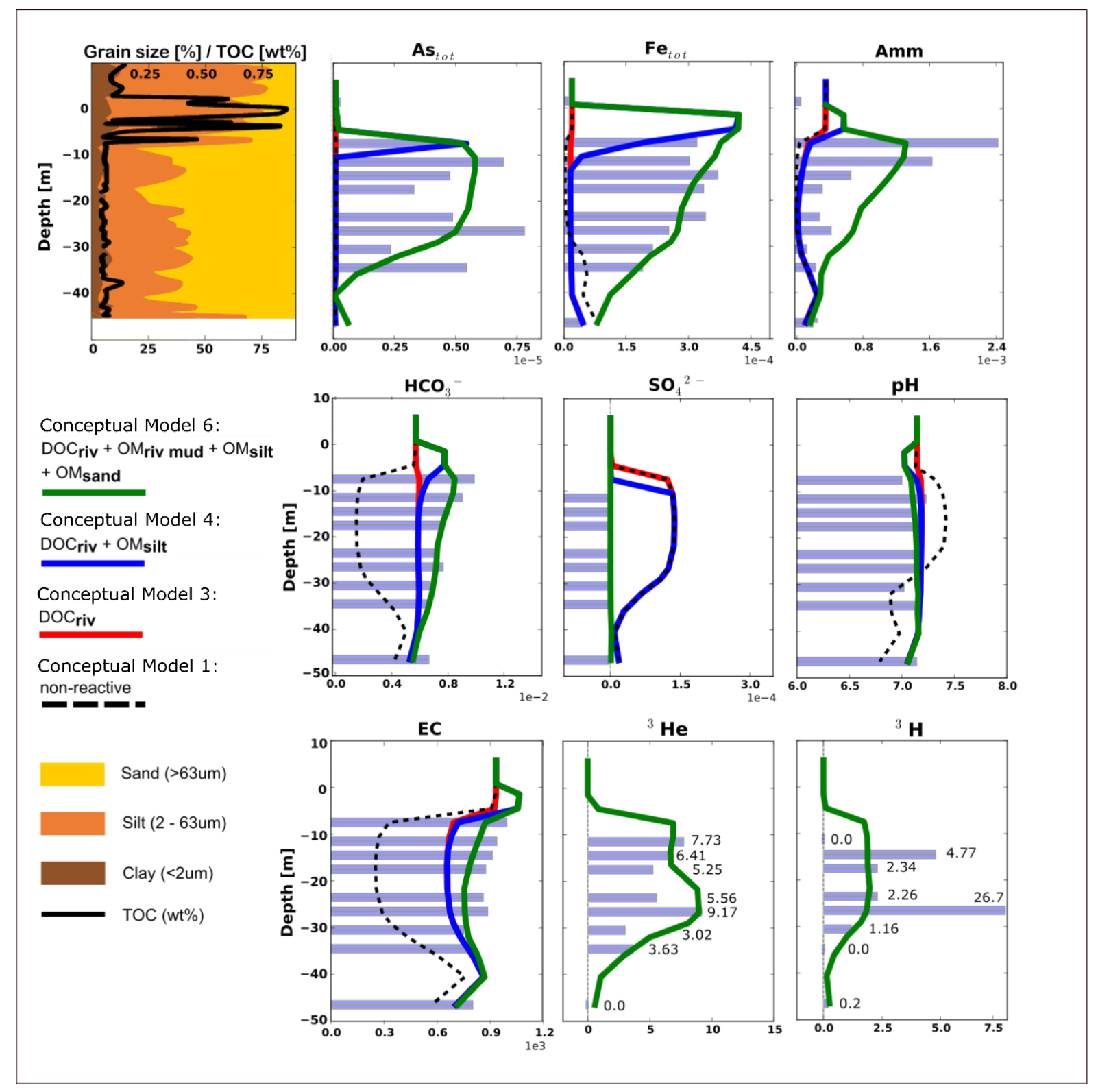

Fig. 5: Observed (blue bars) and simulated (coloured lines) depth profiles of EC [ $\mu \mathrm{S} / \mathrm{cm}], \mathrm{pH}$ and redox sensitive ions [mol/L] at site VPNS-2 (see Fig. 1) in 2010. Observed and simulated ${ }^{3} \mathrm{H}-{ }^{3} \mathrm{He}$ Tri concentrations [TU] are also shown as well as grain size (0-100 \%) and TOC distribution (0-1 wt\%). Simulated data illustrate different organic matter (OM) source terms and their effect on concentration patterns (i) nonreactive: model scenario $\mathrm{CM} 1$; (ii) riverine $\mathrm{OM}$ (DOC riv) source: $\mathrm{CM}$; (iii) $\mathrm{DOC}_{\text {riv }}$ and $\mathrm{OM}$ in silt/clay overburden (OMsilt): CM4; (iv) DOC riv; $\mathrm{OM}_{\text {sitt }}$ and sediment-OM in the river muds and Holocene sands (OMriv mud; OMsand): CM6. 


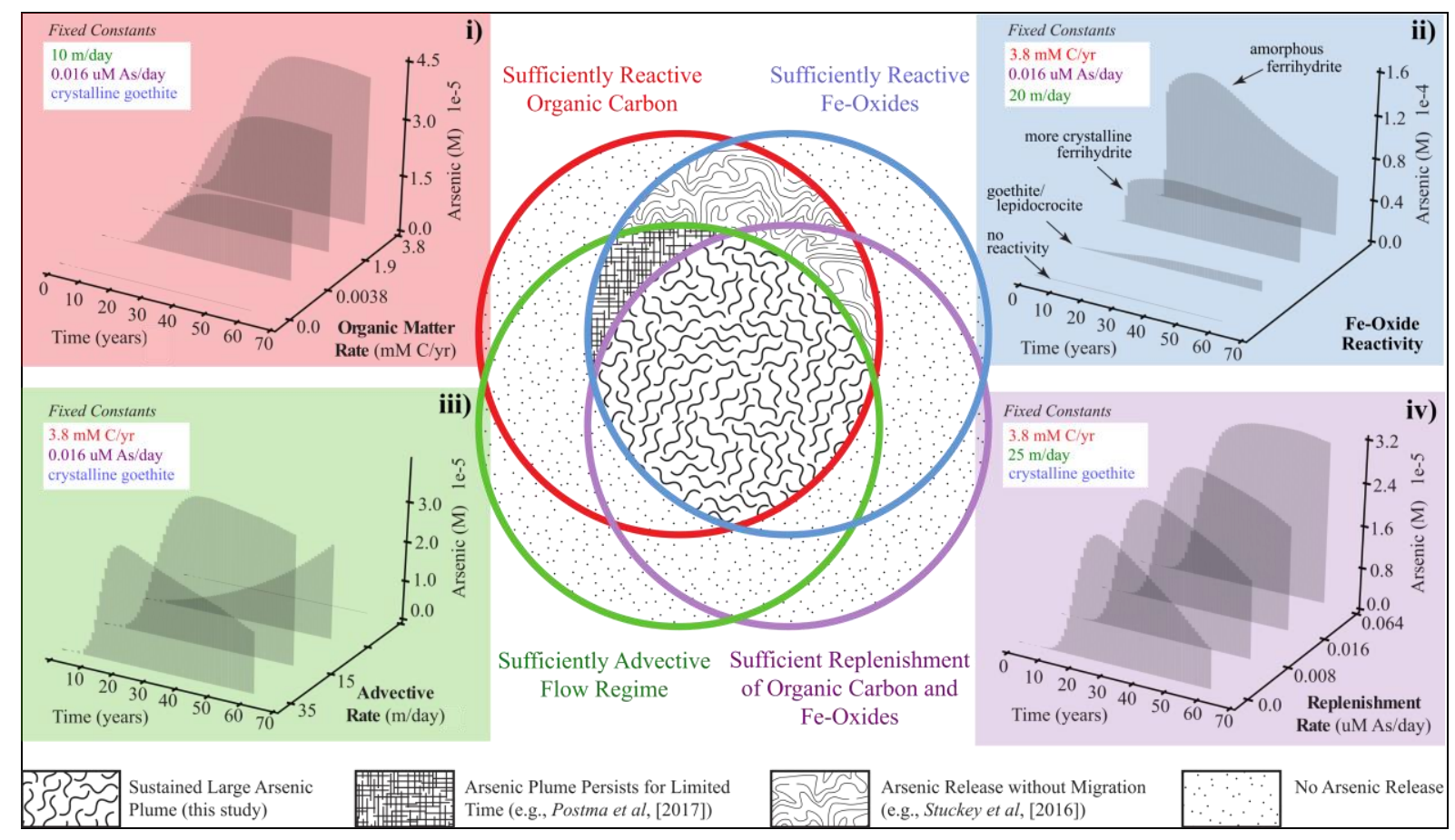

Fig. 6: Model-computed sensitivities of arsenic plume formation at biogeochemical reaction hotspots $(\mathrm{BRH})$ highlighting that sustained arsenic plumes rely on the cooccurrence of (i) labile organic carbon; (ii) reactive As-hosting Fe-oxides; (iii) advection of As-enriched porewaters and (iv) a continuous replenishment of OC and As-hosting Fe-oxides. The ratio between advection and As release rates determines As levels. The joint occurrence or partial absence of (i)-(iv) controls the impact of typical arsenic sources, such as ponds and channels ${ }^{15}$, wetlands ${ }^{14,29}$, buried peat layers ${ }^{4,12}$ and fractured organic-rich clay deposits ${ }^{14,30}$. For example, where replenishment (iv) is absent, such as in non-depositional river sections ${ }^{25}$, a BRHs occurs only temporarily ("hot moment") 26 . Static As-pollution occurs where advection (iii) is absent such as in clay-occupied sections at Van Phuc or low-conductivity aquifers below ponds ${ }^{16}$. 
$411 \quad$ Field site

412 The study site is located near the village of Van Phuc (10 km southeast of Hanoi, Vietnam)

413 where As pollution has been investigated since 2001. The general lithological, hydrological,

414 and geochemical characteristics of the site are well known from previous studies $4,7,10,31,32-34$.

415 A special feature of Van Phuc is that advection of groundwater is induced by massive 416 groundwater withdrawal for the municipal water supply of $\mathrm{Hanoi}^{2,4,7}$. On the other hand, the 417 site displays typical conditions of As-polluted Holocene and Pleistocene aquifers in S/SE Asia 418 with deposited sediments being of a similar origin and depositional environment as the 419 floodplain sediments along the Mekong, Ganges and Brahmaputra delta in Cambodia, 420 Bangladesh and West Bengal. The general stratigraphy is heterogeneous and marked by 421 intercalations of fine to coarse Holocene sands with a burial age of $<5,000$ years, which are 422 in lateral contact with Pleistocene sands, silts and gravels that were deposited $>12,000$ years 423 ago (van Geen et al., $2013^{7}$ ). These are overlain by a confining clay and silt layer 10 to $20 \mathrm{~m}$ 424 thick (Fig. 1). Important examples of other well-studied sites that share similar 425 characteristics include Araihazar (Meghna River, Bangladesh, e.g., van Geen et. al., 2003 ${ }^{35}$ ), 426 Munshiganj (Ganges River, Bangladesh, e.g., Harvey et. al., 2002 ${ }^{18}$ ), Barasat (Hoogli River, 427 West Bengal, e.g., McArthur et. al., $2008^{36}$ ), or Dan Phuong (Red River, Vietnam, e.g., 428 Postma et. al., $\left.2007^{14}\right)$.

430 Due to the large-scale groundwater abstraction at the Hanoi water works, the study site 431 benefits from relatively well-controlled hydraulic flow conditions with groundwater flow 432 directions directed consistently towards a cone of depression beneath Hanoi. This site 433 therefore provides a unique opportunity to determine As migration rates over several 
decades, which is a substantial advantage over many other As-affected locations, where the historic groundwater flow conditions remain far less determined and are often far more 436 complex.

\section{Modelling Approaches and Tools}

439 Based on the hydrogeological site characterisation, environmental tracer data and the records of observed aqueous and solid phase chemistry, a wide range of plausible 441 conceptual models for both the physical processes (flow and nonreactive transport) and the geochemical processes were formulated. Each of the conceptual models was translated into 443 a corresponding numerical model. The USGS flow model MODFLOW ${ }^{37}$ was used to perform 444 the groundwater flow simulations while the reactive multi-component transport model $\mathrm{PHT}^{38}$ was used to simulate solute and reactive transport processes. PHT3D couples the 446 three-dimensional transport simulator $\mathrm{MTSDMS}^{39}$ with the USGS geochemical model PHREEQC $-2^{40}$. The model development was performed in two phases. The first phase focused on developing an understanding and quantification of the flow and solute transport behaviour. Measured environmental tracer data for tritium $\left({ }^{3} \mathrm{H}\right)$ and helium $\left({ }^{3} \mathrm{He}_{\text {Tri }}\right)$ were used as a model calibration target in order to reproduce the historic groundwater flow rates at the study site as accurately as possible. The second phase focused on the identification and quantification of the biogeochemical processes and the analysis of the most plausible conceptual model for the site's reactive transport processes. This included the investigation of different conceptual model variants (CM1 to CM6, Table 1). The PEST++ software ${ }^{41}$ was then used to conduct the calibration phase in parallel via TCP/IP network communications, achieving a joint calibration of flow, solute and reactive transport parameters. 


\section{Model Setup}

Based on earlier investigations (e.g., van Geen et al., 2013 ${ }^{7}$ ) that showed a relatively constant flow direction, the numerical models were constructed as a two-dimensional vertical transect model. The model domain was aligned with the main groundwater flow direction observed in the Pleistocene and Holocene aquifer, i.e., from the SE to NW (Fig. 1). Overall the selected model domain covers a lateral flow distance of $2.78 \mathrm{~km}$, originating at the SW river bank. The selected transect passes several monitoring boreholes and includes two multi-level monitoring devices (VPNS1 and VPNS2) for which high-resolution concentration depth profiles were available (Fig. SI1, 3 and 4).

The Holocene and Pleistocene aquifers, including an overlying clay and silt aquitard section, were discretised into 15 model layers in order to obtain a sufficiently high vertical resolution of the biogeochemical gradients. The simulation period was set to 60 years, commencing in January 1950, i.e., before groundwater abstraction in Hanoi started and before bombderived tritium concentrations impacted ground- and surface water concentrations. In order to represent (i) the variations of atmospheric tritium concentrations and the corresponding variations in the Red River and (ii) the successively changing groundwater flow regime that can be attributed to groundwater extractions in Hanoi, the simulation time was discretised into 12 hydraulically and/or hydrochemically differing stress periods of 5 years length (Fig. SI2).

\section{Implementation of Environmental Tracer Transport}

The transient flow model was calibrated based on measured tritium $\left({ }^{3} \mathrm{H}\right)$ and helium $\left({ }^{3} \mathrm{He}\right.$ tri:

${ }^{3} \mathrm{H}\left(\beta^{-}\right){ }^{3} \mathrm{He}_{\text {tri }}$ ) concentrations to replicate the observed groundwater age distribution at the 
site. Tritium input to the model was based on the atmospheric tritium values reported by the IAEA for Hong Kong (Global Network of Isotopes in Precipitation (GNIP) King's Park station; https://nucleus.iaea.org/) and assigned as time-varying specified concentrations to all model grid cells representing the Red River. Tritium decay and production of helium during advective-dispersive transport was considered through a first-order rate reaction using a half-life of 12.32 yrs, according to:

$$
\frac{d C{ }^{3} H}{d t}=-k{ }_{3}{ }_{H}{ }^{3}{ }_{H} \quad, \quad \frac{d C{ }^{3} H e e_{t r i}}{d t}=+k{ }_{3}{ }_{H}{ }^{3}{ }_{H}
$$

where $\mathrm{C}_{{ }^{3} \mathrm{H}}$ and $\mathrm{C}^{3} \mathrm{He}$ tri are the ${ }^{3} \mathrm{H}$ and ${ }^{3} \mathrm{He}$ tri concentrations and $k_{3}{ }^{3}$ is the first-order rate constant.

\section{Biogeochemical Reaction Network}

Building on the calibrated groundwater flow and solute transport model, the subsequent reactive transport simulations were performed to interpret the hydrochemical observations at Van Phuc. Through the model-based analysis of field observations, which included both the identification of the most plausible conceptual model and the estimation of suitable and plausible model parameters, a mechanistic understanding of the As distribution patterns and of their evolution was derived. The reactive transport model incorporated the mineralogical data that were previously collected for the Holocene sediments along with observed or reconstructed water compositions (Tables 2 and 3). Based on the available data, the reaction network was defined and then successively refined until the observations could be reproduced. The defined reaction network considered the key biogeochemical processes that were hypothesised to govern the major ion and redox chemistry as well as the partitioning behaviours of the trace constituents such as As and phosphate between 
porewater and sediments. The most important biogeochemical process was the oxidation of dissolved (DOC) and sediment-bound organic carbon (SOM), coupled to the reduction of various electron acceptors. At Van Phuc, DOC and SOM mineralisation occurred under aerobic, denitrifying, sulphate-reducing and Fe(III)-reducing conditions. These reactions were considered in the model through a partial equilibrium approach (PEA), which assumes that the oxidation step is the rate-limiting step (e.g., Postma and Jakobsen, $1996^{42}$ ).

510 Consistent with earlier, closely related studies (e.g., Prommer et al., $2006^{43}$, Sharma et al., $5112012^{44}$, Rawson et al., $2017^{47}$ ) the computed rates of OM mineralisation depended on the 512 abundance of multiple electron acceptors.

$$
\begin{aligned}
r_{o m}=\llbracket k_{o x}( & \left.\frac{C_{o x}}{2.9 \times 10^{-4}+C_{o x}}\right)+k_{\text {nitr }}\left(\frac{C_{\text {nitr }}}{1.55 \times 10^{-4}+C_{\text {nitr }}}\right) \times\left(\frac{k_{\text {oxinh }}}{k_{\text {ox inh }}+C_{o x}}\right) \\
& +k_{\text {sul }}\left(\frac{C_{\text {sul }}}{1.0 \times 10^{-4}+C_{\text {sul }}}\right) \times\left(\frac{k_{\text {ox inh }}}{k_{\text {oxinh }}+C_{\text {ox }}}\right) \times\left(\frac{k_{\text {nitr inh }}}{k_{\text {nitrinh }}+C_{\text {nitr }}}\right) \\
& +k_{F e}\left(\frac{C_{F e}}{1.0 \times 10^{-6}+C_{F e}}\right) \rrbracket
\end{aligned}
$$

513 where $r_{\mathrm{om}}$ is the overall degradation rate of $\mathrm{OM}, k_{\mathrm{ox}}, k_{\text {nitr, }}, k_{\mathrm{sul}}$ and $k_{\mathrm{Fe}}$, are the maximum rate 514 constants for OM mineralisation under aerobic, denitrifying, sulphate-, and Fe(III)-reducing 515 conditions. $C_{\mathrm{ox}}, C_{\text {nitr }}, C_{\text {sul }}$ and $C_{\mathrm{Fe}}$ are the concentrations of dissolved oxygen, nitrate, 516 sulphate and Fe(III)-oxides, respectively, and $k_{\text {ox inh }}$ and $k_{\text {nitr inh }}$ are inhibition constants. The 517 reactivity of the different $\mathrm{OM}$ sources within the aquifer, i.e. young $\mathrm{OM}$ in river muds; OM in 518 sand and clay/silt deposits and DOC within the intruding river water was determined 519 through the automatic model calibration procedure. A generic stoichiometric composition 520 of $\left(\mathrm{CH}_{2} \mathrm{O}\right)_{106}\left(\mathrm{NH}_{3}\right)_{11}\left(\mathrm{H}_{3} \mathrm{PO}_{4}\right)_{4}$ was assumed for both DOC and $\mathrm{SOM}^{21}$. 
522 Calcite and Fe(III)-oxides were included in the reaction network as the main minerals

523 affecting the study site's hydrochemical compositions. The exact nature of the Fe(III)-oxides

524 at the site was unknown. A single Fe(III)-oxide phase, represented as $\mathrm{Fe}(\mathrm{OH})_{3}$, was therefore

525 used in the model for simplicity. The solubility of this Fe(III)-oxide, expressed as $\mathrm{K}=$

$526\left[\mathrm{Fe}^{3+}\right] /\left[\mathrm{H}^{+}\right]^{3}$, was determined as part of the PEST++ model calibration procedure. The

527 estimated log $\mathrm{K}$ of +0.23 (Table SI5) corresponds to a micro-crystalline goethite ${ }^{46}$. This is

528 consistent with previously determined solubilities for Fe(III)-oxides in a Holocene sand

529 aquifer $30 \mathrm{~km}$ north of Hanoi along the Red River by Postma et al $(2010)^{24}$, which ranged

530 from lepidocrocite/ poorly crystalline goethite to hematite. It is also consistent with

531 sequential extraction analysis from the Van Phuc site, which suggested that the dominant

532 non-silicate Fe phase in the Holocene sediments was goethite and/or hematite ${ }^{32}$.

534 Replenishment of iron oxides at the river-aquifer interface was included in the model 535 through a zeroth-order rate expression, which replenishes the Fe(III)-oxide pool at a 536 constant rate, consistent with the location of the field site in a depositional environment.

537 The zeroth-order rate constant was included as an adjustable parameter in the automatic 538 model calibration in order to obtain an estimate for the replenishment rate (Table SI5). The 539 composition of the iron oxide was defined to contain $\mathrm{As}(\mathrm{V})$ at an $\mathrm{As} / \mathrm{Fe}$ molar ratio of $5402 \mathrm{mmol} / \mathrm{mol}$. This is in agreement with Postma et al. $(2010)^{24}$ who obtained As/Fe ratios 541 between 1 to $2 \mathrm{mmol} / \mathrm{mol}$ for river sand material obtained from floodplains in Vietnam 542 during laboratory extraction experiments.

544 Sorption of As in the Holocene section of the aquifer was assumed to occur on the surfaces 545 of Fe(III)-oxides. In the model, the total number of sorption sites on the Fe(III)-oxides was 
546 stoichiometrically linked with simulated Fe(III)-oxide concentrations. By doing so, the

547 successively decreasing sorption capacity that results from the reductive dissolution of 548 Fe(III)-oxides was considered ${ }^{47}$. In addition, arsenic can also be liberated as a result of 549 competitive displacement from sorption sites. Sequential extraction analysis by Berg et al $550(2008)^{4}$ and Eiche et al (2009) ${ }^{21}$ showed easily desorbable As to be the by far dominant pool 551 of As throughout the aquifer at the site (Fig. SI1). To allow for a process-based description of 552 competitive sorption effects and the influence from $\mathrm{pH}$ changes on As dynamics, surface 553 complexation models were employed. The generalized two-layer surface complexation 554 model of Dzombak and Morel $(1990)^{49}$ was considered in the reaction network, extended by 555 reactions for $\mathrm{Fe}^{2+}, \mathrm{HCO}_{3}{ }^{-}$and $\mathrm{Si}$ with reaction constants adopted from the literature ${ }^{47-49}$. The 556 densities of strong and weak sites on the Fe(III)-oxides were included as adjustable 557 parameters within the automatic model calibration procedure. For the Pleistocene section 558 of the aquifer, the recently developed generalised surface complexation model of Rathi et al $559(2017)^{31}$ was employed for As and P.

Initial and Boundary Conditions

562 The water compositions that were employed to define the initial concentrations in the model simulations were based on the hydrochemical data collected by Frei $(2007)^{22}$ and van Geen et al. (2013) and through two field campaigns in September 2006 and April 2010 565 (Table 2 and Tables SI1 and SI2). The initial water composition that was attributed to the 566 Holocene aquifer section of the model was taken from monitoring borehole VPNS 4, located 567 about $1.9 \mathrm{~km}$ distance from the Red River. The groundwater from this site was analysed as being old (i.e., pre-bomb) and therefore presumably unaffected by any geochemical changes that could have occurred as a result of the hydrological changes that were induced 
since 1950. However, the assumed initial dissolved arsenic and phosphate concentrations

571 were increased from the measured concentrations to match the measured sorbed arsenic

572 and phosphate concentration ranges in the aquifer sediments and river bed deposits. The

573 portioning between the sorbed and aqueous phase is thereby determined through the

574 electrostatic double layer model (Table 3). The water composition that persisted in the 575 gravel layer (Fig. 2) that is underlying the Holocene and Pleistocene sands differed from the 576 sands and was established on the basis of three sampled horizons with depths $>54$ metres, 577 which accessed the gravel (Table 2). The water composition that was attributed to model 578 grid cells representing the Red River was based on hydrochemical measurements for the 579 Red River, except for tritium. The tritium concentrations were defined in accordance with 580 the time-variant atmospheric tritium values that were reported for Hong Kong (Global concentrations were charge-balanced and equilibrated with respect to the prevailing mineral composition. The assumed initial mineral concentrations in the model simulations were based on the results of earlier sediment analysis ${ }^{7,10,21}$ (Table 3).

\section{Model Calibration Procedure}

The groundwater flow and reactive transport model was calibrated using the nonlinear regression software PEST, which was implemented in parallel on high-performance computing systems via PEST $++{ }^{41}$. The flow and solute transport calibration dataset consisted primarily of the measured helium and tritium concentrations, along with a hydraulic gradient observation, which was based on the average measured water levels between two monitoring bores, AMS12 and AMS16 (Fig 1). The composite, weighted sum of squared residuals (i.e., differences between observed quantities and their model-simulated 
equivalents) was used as the primary objective function to be minimised during the 595 calibration process.

597 There were a total of 18 tritium and 19 helium observations available from various depths; 598 all observations were obtained in $2007^{7,22}$. The weights imposed on each observation of 599 tritium and helium were generally set to 1.0, with some weights being slightly adjusted to 600 reflect their potential inherent measurement and model-structure errors. Since the 601 hydraulic gradient observation had a smaller magnitude (about 1-3 orders) and consisted of 602 only a single observation, it was assigned a weight of $1 \times 10^{5}$ such that it produced a relatively 603 comparable contribution to the composite least-squares objective function.

Estimated model parameters consisted of horizontal and vertical hydraulic conductivity, 606 porosity, and the conductance of the general-head boundary (GHB) condition. Hydraulic conductivity and porosity were parameterised using a zonation method, resulting in 9 zones for each of the three parameter types (Fig. SI 4), i.e., a total of 28 estimated hydrologic parameters.

611 Due to the relatively high degree of parameterisation, the inverse problem was 612 underdetermined. Tikhonov regularisation was employed to alleviate overparameterisation 613 by incorporating prior information, an approximate Bayesian approach ${ }^{41}$. This prior 614 information consisted of an expected vertical anisotropy of 100 for hydraulic conductivity, 615 and a tendency toward homogeneous conditions for porosity values assigned to zones with 616 similar aquifer materials (e.g., zones within the Holocene sediments have a tendency toward 617 similar porosity values). 
619 The geochemical parameters were calibrated jointly with the flow and solute parameters. 620 While the larger-scale groundwater flow and transport patterns in the Holocene aquifer 621 shows a truly three-dimensional behaviour, the simulation of the reactive transport of 622 solutes along the selected vertical transect is thought to be an adequate approximation. 623 Where important hydrochemical data that was required to fill "data gaps" was not collected 624 from wells residing directly on the modelled transect but in its vicinity (Fig. 1), we projected 625 these observations onto the selected transect (AMS15 and VPNS9, Fig. 3).

626 The joint calibration of flow, solute and reactive transport parameters allowed the most 627 appropriate conceptual model for replicating the observed flow and geochemical field data 628 to be revealed as part of the model calibration process. For the conceptual model producing 629 the smallest objective function value, the calibrated hydrochemical and flow/transport 630 parameters are listed in Table SI5 and SI6. These tables also list the parameter bounds and 631 the posterior uncertainty statistics as per the GENLINPRED procedure provided in the PEST 632 software suite, which considers both Bayesian and subspace-based methodologies.

Investigated Model Variants

635 A suite of plausible conceptual and numerical model variants for the site's reactive transport 636 processes were investigated (conceptual model variants $\mathrm{CM} 1$ to $\mathrm{CM} 6$, Table 1). Variant $\mathrm{CM} 6$ 637 provided a numerical implementation which included, besides a comprehensive range of 638 biogeochemical reactions, the entire range of potential organic matter sources within the 639 investigated groundwater system and served as the basis for the inversion process. The 640 systematic comparison between model simulation results and observations thereby allowed 
641 for the process-based model to reveal independently whether a process contributes to the 642 field-observed hydrochemical patterns, i.e., the spatial distribution of major ion 643 compositions, redox conditions and in particular As concentrations. The inversion process 644 revealed that OM sources at the study site had distinctively different reactivities depending 645 on their lithological association, which was explored and illustrated further through model 646 variants $\mathrm{CM} 1$ to $\mathrm{CM} 5$ :

647 - CM1: non-reactive model variant; allows to illustrate the impact of geochemical 648 reactions and to distinguish between transport and reaction-derived concentration 
665 The lack of long-term historical water level and concentration data, especially from the 666 period prior to the reversal of the hydraulic gradient, is a source of model uncertainty. For 667 example, time series of hydraulic head data, which document the deepening of the cone of 668 depression due to increased groundwater abstractions at the Hanoi water works, are scarce. 669 However, this lack of data is largely compensated by the use of age tracer concentrations as 670 additional constraints for the groundwater flow model simulations. These measured 671 environmental tracer concentrations provide a time-integrated measure of river water 672 intrusion. Furthermore, our model-derived interpretation of the regional scale concentration patterns establishes the importance of the river-groundwater interface as a 674 geochemical reaction hotspot. Clearly, the numerical implementation of the interface is, despite the consideration of many process details, still idealised due to the (large) scale of the model domain and the lack of spatially more dense observation data in the proximity of 677 the interface. Future, more detailed investigations of this zone will allow to reveal additional process details and to more tightly constrain model simulations of the interface processes.

\section{Data availability statement}

The geochemical data analysed during this study are included in this article in the 682 supplementary information in Tables S1 and Tables S2. The groundwater age data analysed 683 during this study has been published and is available in van Geen et al. (2013) ${ }^{7}$ and Stahl et 684 al. $(2016)^{10}$ (Table S1). The solid phase chemistry data at the site was available from Eiche et 685 al. $(2008)^{32}$ and Eiche $(2009)^{21}$.

\section{Code Availability}


688 All codes used as part of this study are publicly available and can be accessed freely. The 689 USGS flow model MODFLOW ${ }^{37}$ (https://www.usgs.gov/software/software-modflow) was 690 used to perform the groundwater flow simulations while the reactive multi-component 691 transport model $\mathrm{PHT}^{38} \mathrm{D}^{38}$ was used to simulate solute and reactive transport processes 692 (http://www.pht3d.org/). PHT3D couples the three-dimensional transport simulator 693 MT3DMS $^{39}$ with the USGS geochemical model PHREEQC $-2^{40}$. The PEST++ software suite ${ }^{41}$ 694 was employed for model calibration and uncertainty analysis 695 (http://www.pesthomepage.org/).

696

697 Continued References

69831 Rathi, B., Neidhardt, H., Berg, M., Siade, A. \& Prommer, H. Processes governing 699 arsenic retardation on Pleistocene sediments: Adsorption experiments and model$700 \quad$ based analysis. Water Resources Research 53, 4344-4360 (2017).

70132 Eiche, E. et al. Geochemical processes underlying a sharp contrast in groundwater 702 arsenic concentrations in a village on the Red River delta, Vietnam. Appl Geochem $703 \quad 23,3143-3154(2008)$.

33 van Geen, A. et al. Comparison of arsenic concentrations in simultaneously-collected 705 groundwater and aquifer particles from Bangladesh, India, Vietnam, and Nepal. Appl

$70734 \quad$ Neidhardt, H. et al. Insights into arsenic retention dynamics of Pleistocene aquifer 708 sediments by in situ sorption experiments. Water research 129, 123-132 (2018).

35 van Geen, A. et al. Spatial variability of arsenic in 6000 tube wells in a $25 \mathrm{~km} 2$ area of 710 Bangladesh. Water Resources Research

39, $\quad 1140$ (2003). .doi:10.1029/2002WR001617 
71236 McArthur, J. et al. How paleosols influence groundwater flow and arsenic pollution: a 713 model from the Bengal Basin and its worldwide implication. Water Resources $714 \quad$ Research 44, W11411 (2008). doi:10.1029/2007WR006552.

71537 Harbaugh, A. W. MODFLOW-2005, the US Geological Survey modular ground-water 716 model: the ground-water flow process. US Department of the Interior, US Geological 717 Survey Reston, VA (2005).

71838 Prommer, H., Barry, D. A. \& Zheng, C. MODFLOW/MT3DMS-based reactive 719

720

721

722

727

728

729

730

731

732

733

734 multicomponent transport modeling. Ground Water 41, 247-257 (2003).

39 Zheng, C. \& Wang, P. P. MT3DMS: A modular three-dimensional multispecies transport model for simulation of advection, dispersion, and chemical reactions of contaminants in groundwater systems; documentation and user's guide. (DTIC Document, 1999).

40 Parkhurst, D. L. \& Appelo, C. User's guide to PHREEQC (Version 2): A computer program for speciation, batch-reaction, one-dimensional transport, and inverse geochemical calculations. (1999).

41 Welter, D. E., White, J. T., Hunt, R. J. \& Doherty, J. E. Approaches in highly parameterized inversion-PEST++ Version 3, a Parameter ESTimation and uncertainty analysis software suite optimized for large environmental models. Report No. 2328-7055, (US Geological Survey, 2015).

42 Postma, D. \& Jakobsen, R. Redox zonation: equilibrium constraints on the $\mathrm{Fe}$ (III)/SO4-reduction interface. Geochim Cosmochim Ac 60, 3169-3175 (1996).

43 Prommer, H., Tuxen, N. \& Bjerg, P. L. Fringe-controlled natural attenuation of phenoxy acids in a landfill plume: integration of field-scale processes by reactive transport modeling. Environ Sci Technol 40, 4732-4738 (2006). 
73644 Sharma, L., Greskowiak, J., Ray, C., Eckert, P. \& Prommer, H. Elucidating temperature

737 effects on seasonal variations of biogeochemical turnover rates during riverbank 738 filtration. Journal of Hydrology 428, 104-115 (2012).

73945 Rawson, J. et al. Quantifying reactive transport processes governing arsenic mobility 740 after injection of reactive organic carbon into a Bengal Delta aquifer. Environ Sci $741 \quad$ Technol 51, 8471-8480 (2017).

74246 Schwertmann, U. Solubility and dissolution of iron oxides. Plant and soil 130, 1-25 $743 \quad$ (1991).

$744 \quad 47$ Appelo, C., Van der Weiden, M., Tournassat, C. \& Charlet, L. Surface complexation of 745 ferrous iron and carbonate on ferrihydrite and the mobilization of arsenic. Environ 746 Sci Technol 36, 3096-3103 (2002).

74748 Swedlund, P. J. \& Webster, J. G. Adsorption and polymerisation of silicic acid on 748 ferrihydrite, and its effect on arsenic adsorption. Water Research 33, 3413-3422

749 (1999).

75049 Dzombak, D. A. \& Morel, F. M. Surface complexation modeling: hydrous ferric oxide. $751 \quad$ (John Wiley \& Sons, 1990). 